\title{
Vertical asymmetries and inhibition of return: Effects of spatial and non-spatial cueing on behavior and visual ERPs
}

Authors: Francisco-Javier Gutiérrez-Domínguez, Paula Pazo-Álvarez, Sonia Doallo, Luis J. Fuentes, Laura Lorenzo-López, Elena Amenedo.

This is the peer reviewed version of the following article: Gutierrez-Domínguez, F-J., PazoÁlvarez, P., Doallo, S., Fuentes, LJ., Lorenzo-López, L., \& Amenedo, E. (2014).Vertical asymmetries and inhibition of return: Effects of spatial and non-spatial cueing on behavior and visual ERPs. International Journal of Psychophysiology, 91, 123-131. doi: 10.1016/j.ijpsycho.2013.12.004

This article may be used for non-commercial purposes in accordance with Elsevier and International Organization of Psychophysiology terms and conditions for use of self-archived versions. 
Vertical asymmetries and inhibition of return: Effects of spatial and Non-spatial cueing on behavior and visual ERPs

Authors: Francisco-Javier Gutiérrez-Domíngueza, Paula Pazo-Álvarez ${ }^{a}$, Sonia Doalloa , Luis J. Fuentes $^{\mathrm{b}}$, Laura Lorenzo-López ${ }^{\mathrm{c}}$, Elena Amenedo ${ }^{\mathrm{a}}$.

${ }^{a}$ Universidade de Santiago de Compostela, Spain

${ }^{b}$ Universidad de Murcia, Spain

${ }^{c}$ Universidade de A Coruña, Spain

Corresponding author at: Campus Sur s/n, 15782, Santiago de Compostela, Galicia, Spain. Tel.: +34 981563 100x13916; fax: +34 981528 071. E-mail address: elena.amenedo@usc.es (E. Amenedo). 


\begin{abstract}
The mechanisms underlying inhibition of return (IOR) are still under debate. Besides the probable implication of several processes in its generation, a reason for this uncertainty may be related to experimental factors affecting the presence, time course, and magnitude of IOR. Two of them may be related to the arrangement of the stimuli in the visual field that could cause possible interactions between IOR and response conflict effects (horizontal arrangements) or between IOR and perceptual asymmetries (vertical arrangement). The purpose of the present study was to explore location and color cueing effects with a vertical arrangement of stimuli, free of $\mathrm{S}-\mathrm{R}$ compatibility effects. To examine this possibility, a cue-back task with stimuli in the vertical meridian was employed. Targets could randomly and equiprobably appear at cued or uncued locations, or with cued or uncued color. These cueing effects were analyzed on behavior and ERPs separately for upper and lower visual fields (UVF and LVF). Under location cueing, behavioral responses were slower (spatial IOR) in both hemifields. In the ERPs, N1 reductions were observed in both visual fields although with different modulations in their latency and scalp distribution. In the $\mathrm{P} 3$ rising beginning, posterior negative deflections in the LVF $(\mathrm{Nd})$ and anterior positive deflections (Pd) in the UVF were observed. Under color cueing, P3 amplitude was reduced in the UVF accompanied by no behavioral effects. These results suggest that different patterns of brain activation can be obtained in upper and lower visual fields under spatial- and non-spatial cueing conditions.
\end{abstract}

\title{
Post-print (final draft post-refereeing)
}




\section{Introduction}

When an uninformative peripheral cue appears in our visual field it automatically attracts our attention. If within a short time interval (approximately $250 \mathrm{~ms}$ following the cue) a target is presented at the same location as the cue, response times (RTs) are faster for that target than for a target appearing at a different location. However, if the time between the cue and the target is longer, RTs for targets at the cued location becomes lower. This effect was firstly explained as an inhibitory mechanism that prevents the processing of information appearing at explored locations to optimize the orienting of the visual system to novelty (Posner and Cohen, 1984), and it was later called Inhibition of Return (IOR; Posner et al., 1985). Since its discovery, IOR has been observed in a wide variety of experimental situations within the visual, auditory, and tactile modalities (e.g., Spence et al., 2000). IOR has also been observed across a variety of tasks, including detection, localization, and discrimination (see Klein (2000) for a review), and even in natural scenes (Klein and MacIness, 1999). IOR-like effects have also been observed to nonspatial dimensions of both cue and target stimuli such as color, shape, and semantics (non-spatial IOR; see, for example Chen et al., 2010; Fuentes et al., 1999; Hu et al., 2011). This ubiquity suggests that the mechanisms underlying IOR are important for the selection of information.

Nevertheless, the neural substrates and functional significance of IOR are still under debate. Current evidence indicates that IOR mayarise from a combination of inhibited perceptual processing (Handy et al., 1999; McDonald et al., 1999; Prime and Ward, 2004; Prime et al., 2006), a more conservative response criterion on cued trials relative to uncued trials (Ivanoff and Klein, 2001, 2006), and an inhibition of motor (Pasttöter et al., 2008) and oculomotor programming (Ro et al., 2000). Given the evidence supporting several mechanisms, it has been proposed that IOR may arise from multiple processes (Kingstone and Pratt, 1999). In this context, Taylor and Klein (2000) proposed two mutually exclusive forms of IOR that depend essentially on whether the oculomotor system is activated (the motor form) or suppressed (the perceptual/attentional form). These forms have been recently observed both in behavioral execution and in visual event-related potential (ERP) results (Hilchey et al., 2013; Satel et al., 2013). Besides the probable implication of several processes in the generation of IOR, a reason for the current uncertainty on its origins may be related to several experimental factors affecting the presence, time course, and magnitude of IOR (Klein, 2000). In this regard, the most extensively used design to explore the effects of IOR has been the cue-target paradigm in the visualmodality (for a review, see Klein, 2000). In this paradigm, a peripheral cue is presented before the target stimulus at different cue-to-target time intervals (cue-to-target stimulus onset asynchrony, CTOA), and the differences between the responses tocued and uncued targets are examined. The fact that to obtain an IOR effect a CTOA longer than approximately $250 \mathrm{~ms}$ is necessary has been attributed to the need to disengage attention from the cued location before the presentation of the target stimulus (Posner et al., 1985; but see, for example, Chica and Lupiáñez, 2009; Riggio et al., 2004). However, the cue-target paradigm does not assure that the attentional focus has been disengaged from the cue at the time of target presentation (Prime et al., 2006). To overcome this limitation, an alternative paradigm, called the 'cue-back design', presents a second cue (the cue-back) during the CTOA interval at central fixation. This cue-back does not share any characteristic with either the cue or the target and plays the only role of attracting attention away from the cue to ensure that it has been reoriented away from the cued location.

\section{Post-print (final draft post-refereeing)}


Another factor that may underlie the current uncertainty about the functional locus of the IOR effect is that related to the arrangement of the stimuli in the visual field. In this sense, the presentation of the stimuli along the horizontal axis has been one of the most frequently employed in this context (e.g. Fuchs and Ansorge, 2012; Taylor and Klein, 1998a; Wascher and Tipper, 2004). This arrangement, however, may result in an interaction of IOR effects with other related to the spatial relationships between the location of the target stimulus and the response hand ( $\mathrm{S}-$ $\mathrm{R}$ compatibility). One of the most known is the Simon effect, which has been proposed to interact with IOR (see Ivanoff et al. (2002) for a review; Wang et al., 2013). To overcome possible interactions between IOR and spatial S-R compatibility effects, tasks presenting the stimuli along the vertical axis can be employed. Importantly, the perceptual characteristics of our visual hemifields along the vertical axis present several asymmetries (see Karim and Kojima (2010) for a recent review). On one hand, behavioral studies have found vertical asymmetries favoring the lower visual field (LVF) in contrast-sensitivity (Cameron et al., 2002; Carrasco et al., 2002), spatial resolution (Carrasco et al., 2002; Rezec and Dobkins, 2004), orientation (Raymond, 1994) and hue (Levine and McAnany, 2005). On the other hand, neurophysiological studies have also confirmed the higher sensitivity of the LVF to contrast patterns (Portin et al., 1999), high contrast checkerboards (Fioretto et al., 1995), and non-attended color (Czigler et al., 2004) or movement direction changes (Amenedo et al., 2007). Moreover, when studying visual ERP components, different patterns can be recorded due to the orientation of the cerebral tissue involved in the analysis of the stimuli, depending on the location in the visual field where stimuli are presented (Di Russo et al., 2001; Chica et al., 2010). Consequently, a main objective of the present research was to explore cueing effects with a vertical arrangement of stimuli, free of S-R compatibility effects.

The existing difficulty to characterize the IOR functional significance and its neural locus, led several research groups to examine the underlying electrophysiological mechanisms of behavioral IOR effects, from target presentation to response execution. These studies revealed that it could be possible that a neural effect associated with IOR happens without its concomitant behavioral expression, as Klein (2000) has argued. In this sense, P1 and N1 components, related to information processing in visual areas, and known to be modulated by attention (for a review, see Luck et al. (2000) and Satel et al. (2013)) have been the most studied in IOR research. In this context, previous studies have found amplitude reductions in the P1 component for spatially cued targets (Chica and Lupiáñez, 2009; Chica et al., 2010; McDonald et al., 1999; Prime and Jolicoeur, 2009; Prime and Ward, 2004, 2006; Satel et al., 2013; Tian and Yao, 2008; Tian et al., 2011b; van der Lubbe et al., 2005; Wascher and Tipper, 2004), even when slower reaction times (RTs) were not observed (Doallo et al., 2004; Eimer, 1994; Hopfinger and Mangun, 1998). These effects have been interpreted as reflecting a suppression or inhibition of perceptual processing in visual areas of previously cued stimuli. However, no effects of IOR on P1 have also been reported (Hopfinger and Mangun, 2001; McDonald et al., 1999; Prime and Ward, 2006; van der Lubbe et al., 2005). The N1 component, which is considered as an electrophysiological index of discrimination processes within the focus of visuospatial attention (Vogel and Luck, 2000), has showed more divergent effects of IOR. Thus, reduced N1 amplitude in cued trials has been mainly observed in those studies using designs that included a cue-back stimulus, and in studies requiring a discrimination task (Prime and Ward, 2004, 2006; Prime et al., 2006; Prime and Jolicoeur, 2009). In other designs, enhanced N1 amplitude was found both along with (McDonald et al., 1999; Tian and Yao, 2008) or without (Eimer, 1994) a behavioral IOR effect. Another ERP that has shown cueing effects is the P3 component. The IOR effect on RTs has been also found to be associated

\section{Post-print (final draft post-refereeing)}


with enhanced P3 amplitude on cued trials (McDonald et al., 1999). However, this effect has not been always reported, since Hopfinger and Mangun (2001) and Zhang et al. (2012) did not find P3 modulations when behaviorally significant IOR effects were present. The effects of cueing on P3 have been interpreted as a post perceptual effect more related to endogenous attention processes than to pure IOR (Chica and Lupiáñez, 2009). The comparison of the ERP wave forms between cueing conditions led several groups to analyze negative differences within different latency ranges (called in general Negative difference, $\mathrm{Nd}$ ) in the IOR context, although no consensus has been reached on their direct relation to IOR effects. Thus, McDonald et al. (1999) explained the $\mathrm{Nd}$ component observed in their study (increased negativity within 100-200 ms in cued trials) as an index of sensory refractoriness caused by response to the cue. Posteriorly, Wascher and Tipper (2004) described three independent Nd components: Nd150 (140-160 ms), $\mathrm{Nd} 250(240-260 \mathrm{~ms})$ and $\mathrm{Nd} 310(300-320 \mathrm{~ms})$. They related the Nd150 to sensory refractoriness in the cued location, the $\mathrm{Nd} 250$ to inhibitory processes associated with the demands of the task, and the latter, $\mathrm{Nd} 310$, observed only when a behaviorally IOR effect was found, to the effort to allocate the focus of attention to a previously inhibited location. However, Prime and Ward (2006) and Prime and Jolicoeur (2009) did not relate directly the processes underlying the Ndwith the IOR generation per se.More recently, three differential waves (called Pd200, Nd240, and Nd280) have also been described associated to IOR effects (Tian et al., 2011a).

Taking all the above into account, the purpose of the present study was to explore the neurocognitive correlates (behavioral and ERP data) of spatial and non-spatial cueing effects. To overcome S-R compatibility effects that might interact with IOR effects, a cue-back task with stimuli in the vertical meridian was employed. Finally, due to the well-known vertical asymmetries in visual processing, we tested the possible differences between UVF and LVF when the location and color of target stimuli were cued in a color discrimination task.

\section{Method}

\section{Participants}

Twenty healthy naive volunteers ( 12 females) participated in the experiment. Participants mean age was $24.56 \pm 5.86$ (19-37 years), and two of them were left-handed. All participants reported having normal or corrected-to-normal vision. They obtained a monetary compensation for their participation.

\section{Stimuli and experimental procedure}

During the task (see Fig. 1), one central and two peripheral (external edge $4.5^{\circ}$ of visual angle from the center of the screen) light gray boxes (RGB 200,200,200, $1.5^{\circ} \times 1.5^{\circ}$ of visual angle) were always present on the vertical meridian of a computer screen $(100 \mathrm{~Hz}$ resolution). A central fixation cross (RGB $150,150,150,0.1^{\circ} \times 0.1^{\circ}$ of visual angle) was also present and participants were instructed to maintain central fixation on it during the task performance. Each trial began with a $1500 \mathrm{~ms}$ blank screen (RGB 50,50,50, average luminance $2.4 \mathrm{~cd} / \mathrm{m} 2$ ) that defined the background screen. After this, a blue (RGB 0,0,255, average luminance $8.3 \mathrm{~cd} / \mathrm{m} 2$ ) or red (RGB $175,0,0$, average luminance $8.2 \mathrm{~cd} / \mathrm{m} 2$ ) patch was presented during $100 \mathrm{~ms}$ filling one of the two peripheral boxes ( 0.5 probability). This patch served as a cue for location or color dimension, and it was uninformative with regard to both location and color dimensions of the target. After a new blank screen of $500 \mathrm{~ms}$ duration, a cue-back consisting of a green patch (RGB 0,95,0, average luminance $8.4 \mathrm{~cd} / \mathrm{m} 2$ ) filling the central box was presented for $100 \mathrm{~ms}$. After another blank

\section{Post-print (final draft post-refereeing)}


interval of $1300 \mathrm{~ms}$, a target was presented until response or for a maximum of $1500 \mathrm{~ms}$. Target stimuli consisted of a blue or red patch ( 0.5 probability), identical to the cue, filling the upper or lower box ( 0.5 probability). Target shared color or location dimension with the cue in $50 \%$ of trials. The time interval comprised between the cue onset and the target onset defined a cuetotarget onset asynchrony (CTOA) of $2000 \mathrm{~ms} 1$ (see Fig. 1). Four experimental conditions were obtained by combining cue and target color and location: trials with both target location and color cued by the first peripheral stimulus (Location Old Color Old, LOCO); target location cued, but not color (Location Old Color New, LOCN); target color cued, but not location (Location New Color Old, LNCO); and neither location nor color of the target cued by the first peripheral stimulus (Location New Color New, LNCN). Participants were asked to respond to target color (red or blue) irrespective of its location by pressing one button (Response Box RB-834 model, Cedrus Corporation) with their righthand to one color and another button with their left hand to the other color. The assignment of response hand to each color was counter balanced across participants. The task was divided in 25 blocks of 64 trials, with the different trial conditions randomly intermixed in each block. Short breaks, where lengths were controlled by subjects, were allowed between blocks. In order to examine the differences between spatial and non-spatial cueing and the possible interactions between them, we compared the four trial conditions (LOCN as spatial cueing condition, LNCO as non-spatial cueing condition, LOCO as the interaction condition, and LNCN as the condition free from cueing effects). Moreover, we performed the statistical analyses taking into account each of the visual fields where the target was presented (LVF or UVF).

\section{Recording and analysis}

Behavioral data

Reaction times (RTs) and accuracy were on-line recorded for all participants in all conditions. Only RT values associated with correct responses were considered for data analyses. Responses were considered correct when RTs were faster than 1500 ms.Mean correct RTs and Error rates (\%) were submitted to a repeated measures analysis of variance (ANOVA) with cueing condition (LNCN, LNCO, LOCN, and LOCO), and visual field (LVF vs. UVF) as within-subject factors (SPSS Statistical Package, v19, IBM Inc.). Whenever appropriate, degrees of freedom were corrected by the conservative Greenhouse-Geisser estimate. An alpha level of .05 was used for all analyses. Post hoc comparisons were made to determine the significance of pair-wise contrasts when appropriate, using the Bonferroni adjustment for multiple comparisons.

Electroencephalographic (EEG) recording

The recordings were made in an electrical shielded and sound attenuated room. Participants were sitting in an armchair placed at $112 \mathrm{~cm}$ distance from the computer screen. Continuous EEG activity was recorded with Brain Vision Recorder (Brain Products, Inc.) from 60 scalp Ag- $\mathrm{AgCl}$ electrodes placed according to the extended 10/20 International System. The cephalic electrodes were referred to the nose tip and grounded with an electrode placed at $10 \%$ of the nasion-inion distance above nasion. Vertical and horizontal electrooculogram (EOG) was recorded from above and below the participant's left eye and from the outer canthi of both eyes, respectively. Electrode impedances were kept below $10 \mathrm{k} \Omega$. The sampling rate was $500 \mathrm{~Hz} /$ channel. The EEG signal was continuously amplified $(10 \mathrm{~K})$ and filtered online with a band pass of $0.05-100 \mathrm{~Hz}$.

EEG analysis

\section{Post-print (final draft post-refereeing)}


Vision Analyzer Software (version 2.0, Brain Products, Inc.) was used for off-line processing. The EEG was digitally filtered with a band-pass of 0.1-30 Hz. Filtered EEG was segmented into epochs of $1500 \mathrm{~ms}$ poststimulus and $500 \mathrm{~ms}$ pre-stimulus to obtain the ERPs to the target stimulus for each participant, visual field (LVF, UVF) and cueing condition (LOCN, LNCO, LNCN, LOCO) separately. Ocular artifacts associated with blinks and vertical eye movements were removed from the EEG employing the Gratton et al. (1983) method, and EEG epochs exceeding $\pm 100 \mu \mathrm{V}$, and/or containing horizontal eye movements were rejected and excluded from averaging, as well as epochs associated with incorrect or no responses. After this procedure, a mean percentage of $76.7 \%$ correct trials across conditions was included into the average to obtain the ERP waveforms, and a mean percentage of $16.6 \%$ of trials were rejected from averaging.

To first explore the effects of the experimental manipulation with a blind method for selecting the time intervals and the electrodes with significant differences among cueing conditions, the targetlocked ERP waveforms across all electrodes and along the entire epoch for each participant, visual field, and condition were submitted to separate spatiotemporal analyses with BESA Statistics Software (v1.0, May 2012; BESA GmbH, Inc., http://www.besa.de/products/besa_statistics/). On these data, to calculate the time intervals and the electrodes with significant amplitude differences between conditions in each participant, an initial paired t-test (alpha level 0.05) was computed per data-point, electrode, and participant in each visual field separately. The resulting timewindows with significant differences in amplitudes among conditions were subsequently passed onto a cluster-based permutation testing for each visual field separately with correction for multiple comparisons. In this procedure, clustering in time (across time points) and space (across electrodes) is based on the results of the preliminary t-test. Depending on the cluster-alpha setting, adjacent data points are subsumed to form a cluster. The significance of these data clusters is probed during permutation testing. The main idea behind this permutation test is that if a statistical effect is found over an extended time period in several neigh boring channels, it is unlikely that this effect occurred by chance. For the present analyses, 1000 permutations with a $4 \mathrm{~cm}$ distance between neighbor electrodes, and with an initial alpha level of 0.05 , were executed. Finally, the mean amplitude values of the time intervals and electrodes where permutations showed significant differences were calculated and subsequently submitted to parametric statistical testing by means of analyses of variance (ANOVAs). Thus, the results of these permutation analyses enabled us to objectively select different electrode sites and latency windows for further ERP traditional amplitude analyses. Specifically, for the location-cueing effect, differences were found in the latency range of $\mathrm{N} 1$ within a time interval from 148 to $208 \mathrm{~ms}$ for the LVF at P5, P3, P1, $\mathrm{Pz}, \mathrm{P} 2, \mathrm{P} 4, \mathrm{P} 6, \mathrm{PO} 7, \mathrm{PO} 3, \mathrm{POz}, \mathrm{PO} 4, \mathrm{PO} 8, \mathrm{O} 1, \mathrm{Oz}$ and $\mathrm{O} 2$ electrode sites, and within a time interval from 168 to $188 \mathrm{~ms}$ for the UVF at F3, F1, Fz, F2, F4, FC3, FC1, FCz, FC2, FC4, C3, $\mathrm{C} 1, \mathrm{Cz}, \mathrm{C} 2, \mathrm{C} 4$ electrode sites. The permutation tests also showed differences from 288 to $348 \mathrm{~ms}$ at P5, P3, P4, P6, PO7, PO3, PO4 and PO8 for the LVF, and from 320 to $380 \mathrm{~ms}$ at F3, F1, Fz, $\mathrm{F} 2, \mathrm{~F} 4, \mathrm{FC} 3, \mathrm{FC} 1, \mathrm{FCz}, \mathrm{FC} 2, \mathrm{FC} 4, \mathrm{C} 1, \mathrm{Cz}$, and $\mathrm{C} 2$ for the UVF. As these two latency intervals fell along the rising part of the $\mathrm{P} 3$ wave, difference wave forms were obtained by subtracting LNCN from LOCN conditions in each visual field to better see the cueing effects. We will refer to the resulting waveforms thereafter as $\mathrm{Nd}$ (Negative difference) or Pd (Positive difference) depending on the polarity of the difference associated to the IOR effect. For the color-cueing effect, significant differences were found in the latency range of $\mathrm{P} 3$ wave in a time interval from 418 to 438 ms, only for the UVF at CP3, CP1, CPz, CP2, CP4, P7, P5, P3, P1, Pz, P2, P4, P6, P8, $\mathrm{PO} 7, \mathrm{PO} 3, \mathrm{POz}, \mathrm{PO} 4, \mathrm{PO} 8, \mathrm{O} 1, \mathrm{Oz}$, and $\mathrm{O} 2$ electrode sites. For the comparison between uncued (LNCN) and both spatial and color cued dimensions (LOCO), permutation tests showed

\section{Post-print (final draft post-refereeing)}


differences within the $\mathrm{N} 1$ time range in the LVF from 174 to $222 \mathrm{~ms}$ at $\mathrm{CP} 3, \mathrm{CP} 1, \mathrm{CPz}, \mathrm{CP} 2$, CP4, P3, P1, Pz, P2, P4, PO3, POz, PO4, O1, Oz, and O2 electrode sites, and in the UVF from 168 to $200 \mathrm{~ms}$ at FCz, C1, Cz, C2, CP1, CPz, CP2, and Pz electrode sites. Differences were also found in the $\mathrm{P} 3$ rising interval from 280 to $350 \mathrm{~ms}$ in the $\mathrm{LVF}$ at $\mathrm{P} 7, \mathrm{P} 5, \mathrm{P} 3, \mathrm{P} 4, \mathrm{P} 6, \mathrm{P} 8, \mathrm{PO} 7, \mathrm{PO}, \mathrm{POz}$, PO4, PO8, O1, Oz, and O2 electrode sites, and from 268 to $400 \mathrm{~ms}$ at F3, F1, Fz, F2, F4, FC3, $\mathrm{FC} 1, \mathrm{FCz}, \mathrm{FC} 2, \mathrm{FC} 4, \mathrm{C} 1, \mathrm{Cz}$, and $\mathrm{C} 2$ electrodes in the UVF.

Mean ERP amplitudes in each of the above latency windows were submitted to separate repeated measures ANOVAs, using the Bonferroni adjustment for multiple comparisons when appropriate, with the within-subject factors electrode (with the specific levels for each of the above-referred time intervals and visual field respectively), location cueing (LNCN, LOCN), color-cueing (LNCN, LNCO), and location and color cueing (LNCN vs. LOCO) effects.

\section{Results}

\section{Behavioral results}

Mean RTs and error rates as a function of the cueing condition in each visual field are presented in Table 1. After removing from the behavioral data those trials with incorrect responses, an average of $95.3 \%$ of correct trials across conditions was included in the statistical analyses.

On RT values, the repeated measures ANOVA showed significant effects of visual field (RT were $6.04 \mathrm{~ms}$ faster for LVF, $\mathrm{F}(1,19)=7.98 ; \mathrm{p} \mathrm{b} .011)$, and cueing condition $(\mathrm{F}(3,57)=8.86 ; \mathrm{p} \mathrm{b} .0001)$, but analyses did not reveal any statistically significant interaction between cueing condition and visual field. Bonferroni adjustment for comparisons among the cueing conditions showed a significant $11.79 \mathrm{~ms}$ increase in RT for spatial cueing condition (LOCN) compared to the uncued (LNCN) condition ( $\mathrm{p} \mathrm{b}$.032), but not for non-spatial cueing. Moreover, Bonferroni corrected comparisons showed that the spatial and colorcued condition (LOCO) showed the largest significant differences with both spatial uncued conditions: $15.28 \mathrm{~ms}$ slower compared to LNCN ( $\mathrm{p}$ b .0001), and $11.29 \mathrm{~ms}$ slower compared to LNCO ( $\mathrm{p} \mathrm{b}$.006). No significant differences were found between spatial and color cued trials (LOCN vs. LNCO). Finally, no effects of visual field $(\mathrm{F}(1,19)=1.30 ; \mathrm{p}=.27)$ or cueing condition $(\mathrm{F}(1,19)=1.05 ; \mathrm{p}=.38)$ were observed on error rates.

\section{Event-related potential (ERPs) results}

Figs. 2-5 display the grand-average ERP waveforms across cueing conditions and visual fields. A visual inspection of the waveforms in Fig. 2 shows that the N1 component distribution was slightly lateralized over right centro-parietal sites for targets in the UVF, but it was of higher amplitude and more bilateral at posterior electrodes in the LVF. Along with N1, P1 showed more positive values in the UVF compared with the LVF. In the P3 latency range, larger amplitudes for UVF targets were apparent. Additionally, at the P3 rising (Fig. 3), under spatial cued conditions (LOCN) compared to uncued conditions ( $\mathrm{LNCN}$ ), the waveforms were more negative (referred to as Nd thereafter) in the LVF, while in the UVF they were more positive (referred to as Pd thereafter). Moreover, in the subtraction wave forms (LOCN minus LNCN) the Nd showed a slight left-lateralized distribution at parietal and parietooccipital electrodes while the Pd was fronto-centrally distributed in the UVF (see Fig. 3).

Location cueing effects

\section{Post-print (final draft post-refereeing)}


Differences between location-cued (LOCN) and uncued (LNCN) conditions were observed at the $\mathrm{N} 1$ and $\mathrm{Nd} / \mathrm{Pd}$ latency ranges. At the $\mathrm{N} 1$ latency range, the differences were statistically significant from 148 to $208 \mathrm{~ms}$ in the $\operatorname{LVF}(\mathrm{F}(1,19)=16.47, \mathrm{p}<.001)$, and from 168 to $188 \mathrm{~ms}$ in the $\operatorname{UVF}(\mathrm{F}(1,19)=6.26, \mathrm{p}<.02)$. These differences consisted in an $\mathrm{N} 1$ amplitude reduction to location-cued trials, as it is apparent from Fig. 2. The main effect of electrode was significant in $\operatorname{UVF}(\mathrm{F}(14,266)=4.68, \mathrm{p}<.02, \varepsilon=.145)$, but not in $\operatorname{LVF}(\mathrm{F}(14,266)=1.68, \mathrm{p}<.18, \varepsilon=.225)$. Maximum differences were obtained in parieto-occipital sites (maximum amplitude difference at $\mathrm{PO} 4,1.45 \mu \mathrm{V}, \mathrm{p}<.0001$ ) in the LVF, and in centro-frontal sites (maximum amplitude difference at FC4, $0.932 \mu \mathrm{V}, \mathrm{p}<.01$ ) in the UVF. At the Nd/Pd latency ranges (Fig. 3), statistically significant effects of location cueing $(\mathrm{LVF}, \mathrm{F}(1,19)=4.92$, $\mathrm{p}<.04 ; \mathrm{UVF}, \mathrm{F}(1,19)=7.14, \mathrm{p}<.01)$ and electrode site $(\mathrm{LVF}, \mathrm{F}(7,133)=9.38, \mathrm{p}<.0001, \varepsilon=.404 ; \mathrm{UVF}, \mathrm{F}(7,133)=15.76, \mathrm{p}<.0001$, $\varepsilon=.164$ ) were found. As previously referred when describing the waveform characteristics across conditions and visual fields, these differences reversed in polarity in each visual field ( $\mathrm{Nd}$ in the LVF; Pd in the UVF), appeared later in the UVF (320-380 ms) than in the LVF (288-348 ms), and their scalp distribution was posterior in the case of $\mathrm{Nd}$, and anterior for Pd. Specifically, in the LVF, maximum differences were found in lateral positions in parietal and parieto-occipital sites, and they consisted in an increased negativity $(\mathrm{Nd})$ under location cueing conditions (maximum amplitude difference at PO7, $1.35 \mu \mathrm{V}, \mathrm{p}<.01$ ). However, in the UVF, maximum differences were found in frontal, fronto-central and central sites and they consisted in an increased positivity $(\mathrm{Pd})$ under location cueing conditions (maximum amplitude difference at $\mathrm{FC} 1,-1.11 \mu \mathrm{V}, \mathrm{p}<.01)$.

Color cueing effects

The overall effect of color-cueing (Fig. 4) was significant only in the UVF and from 418 to 438 ms $(\mathrm{F}(1,19)=7.42, \mathrm{p}<.01)$. Colorcued trials $(\mathrm{LNCO})$ showed lower amplitudes than uncued trials $(\mathrm{LNCN})$, reaching themaximum difference at parieto-occipital electrodes (maximum amplitude difference at $\mathrm{POz},-1.35 \mu \mathrm{V}, \mathrm{p}<.01)$. The main effect of electrode was significant $(\mathrm{F}(21,399)=16.52, \mathrm{p}<.0001)$, indicating that $\mathrm{P} 3$ was significantly reduced for color-cued trials at all electrodes analyzed (Fig. 4). Finally, no significant interactions between electrode and color-cueing were found $(\mathrm{F}(21,399)=.89, \mathrm{p}<.61)$.

\section{Interaction between spatial and color cueing effects}

In the analyses comparing uncued (LNCN) with spatial and color cueing (LOCO) conditions, we obtained a similar pattern than with the LNCN vs. LOCN comparison, with significant differences in the $\mathrm{N} 1$ and $\mathrm{Nd} / \mathrm{Pd}$ latency ranges. At $\mathrm{N} 1$ in the LVF, we found effects of cueing from 174 to $222 \mathrm{~ms}(\mathrm{~F}(1,19)=8.17 ; \mathrm{p}<.010)$. LOCO trials showed $\mathrm{N} 1$ reduction compared with uncued from centro-parietal to occipital electrodes (maximum amplitude difference at PO4, $-1.38 \mu \mathrm{V}, \mathrm{p}<$ .007) (Fig. 5). The main effect of electrode was not significant $(\mathrm{F}(15,285)=1.87 ; \mathrm{p}<.158 ; \varepsilon=$ $.164)$, neither the interaction between cueing and electrode $(\mathrm{F}(15,285)=.725 ; \mathrm{p}<.521 ; \varepsilon=.171)$. At the UVF, the cueing effects were found in $\mathrm{N} 1(168$ to $200 \mathrm{~ms})(\mathrm{F}(1,19)=5.77 ; \mathrm{p}<.027)$ from fronto-central to parietal electrode sites (maximum differences at $\mathrm{Pz},-1.94 \mu \mathrm{V}, \mathrm{p}<.029$ ). Electrode effect was significant $(\mathrm{F}(7,133)=3.69 ; \mathrm{p}<.044 ; \varepsilon=.235)$, but not the interaction between electrode and cueing effects $(\mathrm{F}(7,133)=.816 ; \mathrm{p}<.441 ; \varepsilon=.263)$.

At Nd/Pd latency ranges, statistical analyses showed significant effects of electrode site (LVF, $\mathrm{F}(13,247)=12.20, \mathrm{p}<.0001, \varepsilon=.221 ; \mathrm{UVF}, \mathrm{F}(12,228)=10.61, \mathrm{p}<.0001, \varepsilon=.152)$ and cueing condition $(\mathrm{LVF}, \mathrm{F}(1,19)=7.04, \mathrm{p}<.016 ; \mathrm{UVF}, \mathrm{F}(1,19)=7.48, \mathrm{p}<.013)$, but statistical

\section{Post-print (final draft post-refereeing)}


significance for the two-way interaction was not found (LVF, $\mathrm{F}(13,247)=2.25, \mathrm{p}<.083, \varepsilon=.263$; UVF, $\mathrm{F}(12,228)=1.34, \mathrm{p}<.272, \varepsilon=.127)$. The scalp distribution of cueing effects in the LVF was lateral and posterior, from parietal to occipital sites, and more negative (Nd) in LOCO than in $\mathrm{LNCN}$ condition (maximum differences at PO7, $1.70 \mu \mathrm{V}, \mathrm{p}<.008$ ). In the UVF, the main differences were localized from frontal to central electrodes, reversing the polarity at these sites, with larger positive amplitudes (Pd) in LOCO condition compared to LNCN condition (maximum amplitude differences at $\mathrm{FC} 1,-1.00 \mu \mathrm{V}, \mathrm{p}<.005)$ (Fig. 5).

\section{Discussion}

The main objective of the present study was to analyze the effects of spatial and non-spatial cueing on behavioral execution and on EEG evoked activity. For that purpose, RTs, error rates and ERPs were obtained under location and color cueing conditions in a cue-back design with long CTOAs (2000 ms). To control for possible interactions between cueing effects and spatial compatibility between target location and response side, the stimuli were presented along the vertical meridian.

Moreover, as vertical asymmetries in visual processing depending on the visual field could affect the results of this study (Karim and Koyima, 2010; Thomas and Elias, 2011), we analyzed the lower and the upper visual fields separately. The results revealed different effects of location and color cueing on EEG evoked activity. Moreover, differences between visual fields were observed in location and color cueing effects on EEG evoked activity.

\section{Behavioral data}

Behaviorally, the typical RT slowing, along with an absence of differences between error rates, were observed under location cueing conditions (spatial IOR) in both visual fields but not under color cueing conditions. In a previous study, Chen et al. (2010), starting from the premise that the orienting and the executive networks interact in contexts of visuospatial attention (Posner and Petersen, 1990), designed an IOR experiment in which they used combinations of location and color cueing similar to that of the present study, but employing a horizontal arrangement of stimuli. They found neurofunctional (fMRI) patterns that led them to conclude that the orienting network (more related to spatial IOR) and the executive network (more active under nonspatial IOR) interact in such a way that when one of them was inactive (i.e. uncued location or color conditions) the other (i.e. cued color or location conditions, respectively) showed more IOR effects. In contrast with the present results, Chen et al. (2010) found a significant color cueing effect (indicative of non-spatial IOR) on the RT. In Chen et al.'s research, the color effect was smaller than the location effect and only appeared at spatially uncued locations. The authors attributed their findings to the activation of the orienting and the executive networks of attention under spatial and non-spatial IOR respectively.

The demands of the present task were similar to that of the Chen et al. (2010) discrimination task, although different results were found regarding color cueing effects. To explore the causes of this discrepancy, differences in task parameters should be described more closely. Although both designs share many features, they specifically differ in two: the presentation of the stimuli on the horizontal axis, and the use of shorter CTOAs (650-750-850 ms) in Chen et al., study (2010). It could be possible that one or two of these features could mask or prevent the effects of color cueing; for example, if the spatial and nonspatial cueing effects would have a different temporal pattern, nonspatial inhibitory effects could disappear with long CTOAs while the spatial IOR

\section{Post-print (final draft post-refereeing)}


could be still working2 (Langley et al., 2007). Therefore, the discrepancies observed between our data and those of Chen et al. could be explained by differences in this aspect of the experimental design. Moreover, in the study by Chen et al. (2010), the above-referred location-based and colorbased inhibitory effects were observed when the color was the relevant feature in their discrimination task. However, they did not observe color cueing effects when they instructed the participants of their study to ignore color and to respond to the location of the target stimuli. Based on these previous findings, we decided to use the color discrimination task to explore both cueing effects in the present study. As an anonymous reviewer suggested, there exists the possibility that the spatial cueing effects observed in our discrimination task could be explained by the relevance of the visual dimension (i.e. color). Therefore, and in order to assess whether a similar pattern of results emerges when location is task relevant, a behavioral experiment with the same parameters than in the original task was designed, with the sole exception that the location of the target was the relevant dimension for responding to target stimuli. The results of fourteen participants (for extended information, see Appendix A) showed again a significant cueing condition effect that was restricted to location cueing. Differences between visual fields or in the interaction between cueing condition and visual field were not found. Therefore, the pattern of increased response times (RTs) observed under spatial cueing conditions and the absence of significant differences due to color cueing resembled the results obtained in the location discrimination task by Chen et al. (2010). This finding suggests that the location cueing effects reported here are not likely to be explained by the task-relevance of the visual dimension.

Considering other previous studies in which only the color cueing was manipulated during a detection task, no convincing evidence has been found that IOR can be tagged to this non spatial feature (Kwak and Egeth, 1992; Taylor and Klein, 1998b).

However, when location cueing was combined with other features such as color, data provided time- and task-dependent complex results. Specifically, Hu et al. (2011) found, with a detection task, that nonspatial IOR-like effects occurred when the color feature appeared at the cued location. With a similar design but employing a discrimination task, Hu and Samuel (2011) even found the opposite, i.e. a facilitation of color cueing at short SOAs (200 and $350 \mathrm{~ms}$ ). The color cueing effects observed in the first experiment by $\mathrm{Hu}$ et al. (2011) could be interpreted as an inhibition of the processing of the color when it appeared at the cued location (i.e. 'inhibitory tagging', Fuentes et al., 1999). In the present study, the behavioral data showed only a spatial IOR effect. Moreover, no differences were found between LNCN and LNCO conditions, which are consistent with the findings in the $\mathrm{Hu}$ et al. (2011) detection task experiment.

Since color was the relevant feature in the task of the present study, it is supposed that attention to color was endogenously controlled (top-down orientation) to perform it. On the contrary, location was a non-relevant feature, but spatial attention would be exogenously oriented (bottomup) in order to respond to a relevant stimulus, i.e. the target. Endogenous and exogenous orienting of attention have been proposed to be implemented in overlapping, although partially segregated, brain circuits that involve dorsal and ventral fronto-parietal networks, respectively (Andersen et al., 2009; Chica et al., 2006; Corbetta and Shulman, 2002; Klein and Shore, 2000; Lupiañez et. al., 2004; for a recent review see Chica et al., 2013). Specifically, Chen et al. (2010) indicated that the exogenous and the endogenous attentional capture are controlled by the orienting and executive neural networks respectively.

\section{Post-print (final draft post-refereeing)}


According to this segregation, the existence of a spatial IOR but not a non-spatial inhibitory effect in our data seems to suggest, in agreement with previous studies (Chica et al., 2006; Chica and Lupiáñez, 2009; Lupiáñez et al., 2004) that mainly exogenous attentional mechanisms are acting in the present task to evoke spatial IOR effects.

\section{ERP data}

When comparing location-cued trials (LOCN)with the uncued trials (LNCN), the ERPs showed significant spatial IOR effects on the N1 component latency range in both visual fields that consisted in lower amplitudes under location cueing. However, the scalp distribution of maximum differences varied depending on the visual field where the target was presented. In the LVF, differences were larger in parietooccipital sites, whereas in the UVF these differences showed a centrofrontal distribution. Moreover, at the rising part of $\mathrm{P} 3$, two different location cueing effects were observed. While in the LVF an Nd was apparent at posterior electrode sites to LOCN trials, in the UVF the same kind of trials elicited a Pd at anterior electrode sites. Finally, the comparison of color-cued trials (LNCO) with the uncued trials ( $\mathrm{LNCN}$ ) showed significant differences in the P3 latency range in the UVF only, indicating that P3 was significantly reduced for color-cued trials mainly at centro-parietal, parietal, parieto-occipital and occipital electrode sites. Considering the location and color cued condition (LOCO), as far as we know there are only previous behavioral (Hu and Samuel, 2011; Hu et al., 2011; Riggio et al., 2004) or fMRI (Chen et al., 2010) studies that have compared the effect of color and location jointly, but none of them have employed ERP analysis.

In the present study, no P1 amplitude modulations were found and the earliest effect of IOR on ERPs was in the N1 latency range. Previous results in the literature, although with discrepancies, showed amplitude modulations at earlier time intervals, specifically at P1 latency. Related to this, there are studies that have found P1 reductions under IOR conditions (Chica and Lupiañez, 2009; McDonald et al., 1999; Prime and Jolicoeur, 2009; Prime and Ward, 2004, 2006; Satel et al., 2013; Tian and Yao, 2008; Tian et al., 2011b; van der Lubbe et al., 2005; Wascher and Tipper, 2004). Such a reduction was generally related to an inhibition of the processing of previously cued stimuli in visual areas (Wascher and Tipper, 2004), suggesting that this modulation at early stages of visual processing indicates a possible causal role of P1 in IOR (Prime and Ward, 2006).

However, other studies did not find P1 reductions associated with IOR (Hopfinger and Mangun, 2001; Satel et al., 2012), or even they found differences in P1 amplitude when behaviorally IOR effects were not present (Doallo et al., 2004; Eimer, 1994; Hopfinger and Mangun, 1998). The present study agrees with those that have not found IOR effects on P1 component although, and as suggested by a reviewer, this effect could be related to sensory attenuation processes due to the long 2000 ms CTOA employed here. A recent research by Satel et al. (2012) also offers an interesting explanation of these discrepancies that should be further explored. Satel et al. (2012) aimed at examining whether the P1 modulations by spatial IOR are associated with retinotopic or with spatiotopic reference frames employed to inhibit the visual processing of previously cued targets. To fulfill this objective, they manipulated retinal and environmental coordinates in the visual field to dissociate spatiotopic (environmental) from retinotopic (retinal) reference frames by introducing an eye movement between the cue and the target onset. They found that early ERP reductions $(\mathrm{P} 1)$ were more closely related to retinotopic than spatiotopic cueing effects, whereas later effects such as $\mathrm{Nd}(220-300 \mathrm{~ms})$ were associated with spatiotopic effects of IOR. The authors claimed that previous studies employed designs that could confound retinal and spatial

\section{Post-print (final draft post-refereeing)}


references, so it remains unclear whether the P1 modulations observed are due to IOR effects. This confound could be also present in our study. Taking all the above into account, the meaning of P1 modulations under IOR remains under debate, and might reflect other phenomena involved in visual information filtering, inhibiting irrelevant features or increasing the signal-to-noise ratio to allowan early categorization of the stimulus in the visual system(Chica et al., 2010; Klimesch, 2011).More recently, Satel et al. (2013) offered an additional explanation to the P1 reductions associated with behavioral IOR. Starting from the two mutually exclusive forms of IOR proposed by Taylor and Klein (2000) they found that P1 reductions were correlated to behavioral IOR only when the oculomotor system was actively suppressed (instruction to maintain fixation), suggesting that P1 modulations may be associated with the perceptual/attentional form of IOR. In the present study ocular movements were not permitted so, following this line of explanation, the perceptual/attentional form of IOR could be recruited. However, as stated above, no P1 modulations were found in this study. The explanation of such discrepancy may be that P1 effects, due to their shorter time course, could be lost with the CTOA employed here.

The results regarding IOR effects on N1 component are also divergent in the literature. Different patterns have been observed in N1 amplitude modulations associated with IOR. Thus, spatial IOR has been found to increase N1 amplitude (Tian and Yao, 2008), to decrease it (Prime and Jolicoeur, 2009; Prime and Ward, 2004, 2006), or even to not affect it (Hopfinger and Mangun, 2001; Satel et al., 2012; Van der Lubbe et al., 2005; Wascher and Tipper, 2004). In the present study, the effect of spatial IOR resulted in a reduction of its amplitude under location cueing conditions with differences in its distribution in each visual field (parieto-occipital in the LVF, and centro-frontal in the UVF). Considering the conjoint ERP expression of color and location cueing effects (LOCO), we could observe similar latency and amplitude differences for LOCN and LOCO at N1. The electrode sites were similar too, but slightly posterior and closer tomidline in the UVF, and extended to centro-parietal electrodes but with less effect at lateral electrode sites in the LVF. These results could provide further evidence to consider that only the location effects are acting at these conditions without the influence of color cueing. These results agree with those of Prime and Ward (2004, 2006) and of Prime and Jolicoeur (2009). In Prime and Ward (2006), three possible causes of $\mathrm{N} 1$ reductions were suggested: the presence of a cue-back event, the vertical arrangement of stimuli, and the use of long CTOAs. In a posterior paper, this group (Prime and Jolicoeur, 2009) reached the conclusion that the cue-back presence was the main cause of the reduction in the early components, including N1. However, reviewing more closely the studies on N1modulations associated to IOR, a design characteristic that may explain better these divergent effects shows up. Specifically, a target detection task was employed in the studies that found no N1 modulations (Hopfinger and Mangun, 2001; Satel et al., 2012; Van der Lubbe et al., 2005; Wascher and Tipper, 2004), while a discrimination task was required in studies that found N1 reductions (Prime and Jolicoeur, 2009; Prime and Ward, 2004, 2006). Previous experiments in the context of visuospatial attention have found N1 amplitude modulations to be related to visual discrimination processes (Van der Lubbe et al., 2005; Vogel and Luck, 2000). Taking this into account, it seems likely thatN1 ismodulated by spatial IOR if discrimination mechanisms are acting, as in the present study, but not if only a detection process is required.

Besides P1 and N1 components, several differential waves have been analyzed as IOR indexes resulting from the effects on ERP amplitudes falling within latency intervals that did not coincide specifically with the peak of any component (Eimer, 1994; McDonald et al., 1999; Prime and Jolicoeur, 2009; Prime and Ward, 2004, 2006; Satel et al., 2012; Tian et al., 2011a; Wascher and Tipper, 2004). Among these waves, three of them share polarity (more negative under IOR

\section{Post-print (final draft post-refereeing)}


effects, called in this case Nd), distribution (parietal and occipital regions), latency (approximately 200-300 ms) and association with behavioral spatial IOR effects: the Nd310 observed in Wascher and Tipper (2004), the Nd in Satel et al. (2012), and the Nd240 and Nd280 in Tian et al. (2011a). Moreover, in one case (Tian et al., 2011a) a positive difference in amplitude with a posterior scalp distribution (called Pd200) was also observed associated with behavioral IOR effects. In the present study both types of effects were observed to be associated with spatial IOR, although they were dependent on the visual field. Specifically, in the LVF an Nd similar to the aforementioned differential negative waves was observed with in similar latency ranges, scalp distribution and association with spatial IOR effects. However, in the UVF the difference in amplitude between spatially cued and uncued conditions appeared slightly later, in anterior electrode sites, and with positive polarity $(\mathrm{Pd})$. The waveforms in LOCO condition are again quite similar to those in the LOCN condition. In this sense, the Nd appeared in LVF at posterior and lateralized electrode sites but extended to parietooccipital electrodes close to midline. The Pd was recorded at the same frontal to parietal sites in both LOCN and LOCO condition swith a similar latency, but with the only difference that significant effects in LOCO vs. LNCN lasted more than in the LOCN vs. LNCN conditions. Considering that the lack of color cueing effects reported in the present paper was reported in previous research with color discrimination tasks (Hu and Samuel, 2011), and according to the N1 results and to the behavioral data, it seems plausible that the similar ERP pattern in LOCO and LOCN conditions be due to location cueing effects. Taking into account the larger attentional resolution and the greater exogenous effects of spatial attention observed in the LVF (He et al., 1996; Fuller et al., 2008), the Nd observed here could be interpreted as an N2-like effect reflecting a re-focusing of spatial attention into a target stimulus appearing at a location where discrimination processes had been previously inhibited (Hopf et al., 2000, 2004;McDonald et al., 2009). The positive deflection observed under spatial IOR in the UVF might be related to the elicitation of an orienting response to select a target stimulus at a previously inhibited location. In this sense, the spatial cueing of target could trigger an anterior P2-like effect that would be related to an extra evaluation of, and/or a conflict resolution in working memory, in trials with targets presented in previously inhibited locations (Du et al., 2007; Gajewski et al., 2008; Potts, 2004).

P3 was the only ERP component that showed significant differences associated with color cueing conditions that resulted in an amplitude reduction when the color of the target was equal to the color of the uninformative cue. Moreover, P3 was not affected by spatial cueing. To our knowledge, the effects of color cueing on this component have not been studied. However, effects on P3 elicited by spatially cued targets have been previously reported in discrimination tasks (Chica and Lupiáñez, 2009) and Go/Nogo tasks (Nogo-P3 in Prime and Jolicoeur, 2009; Tian and Yao, 2008), but not in detection tasks (Hopfinger and Mangun, 2001; McDonald et al., 1999). Eimer (1994) found larger amplitudes for P3 in uncued trials for a location task (but not for an identity task) without IOR effects on RT, or even with facilitation effects. In his article, he proposed that a negativity related to the attended stimulus could be occurring at the same time than P3. It is possible that the P3 modulation observed in the present results may depend on postperceptual processes (Prime and Jolicoeur, 2009), perhaps linked to decision making or to the link of perception with motor response processes (McDonald et al., 1999; Tian and Yao, 2008). Examining our results, the lack of spatial IOR effects on this component, and the absence of modulations of earlier components related to color cueing may suggest that this wave is not directly related to the IOR mechanism but to a more general post-perceptual evaluation and/or selection of the relevant dimension (i.e. the color of the target in the present task).

\section{Post-print (final draft post-refereeing)}


In summary, the aim of the present research was to explore the possible differences between UVF and LVF when the location and color was cued in a color discrimination task. We found spatial cueing effects on RTs, but color cueing failed to show behavioral effects, even when the relevant dimension of the task was reversed. These results indicate that, at least with the design employed in the present study, only location cueing is associated with IOR. Electrophysiologically, under spatial IOR we have found N1 amplitude reductions in both upper and lower visual fields although with different scalp distribution (posterior in the LVF, and more anterior in the UVF). Significant amplitude modulations in the rising part of P3 were also observed under location cueing. However, the polarity and scalp distribution of such modulations differed depending on the visual field where location cueing occurred (a posterior Nd in the LVF, and an anterior Pd in the UVF), which can suggest that different underlying processes are activated depending on the visual field where the target has to be discriminated. Under color cueing, results showed reduced P3 amplitude only in the UVF. As the P3 modulation was found in the absence of behavioral effects, it is likely that it could be indexing a process different from IOR.

The use of a vertical arrangement of stimuli allows avoiding of spatial compatibility effects between stimuli and response (e.g. Simon effect), but the results of the present study suggest that with these displays, it would be necessary to explore each visual field separately, attending to the differences found in the neurocognitive IOR expression. In this regard, the different modulations observed in the rising period of P3 under spatial cueing (posterior $\mathrm{Nd}$ and anterior Pd effects in this study) that suggest that the activation of two different processes depending on the visual field of stimulation need further study to reach conclusions on the underlying processes. The other remaining questions should be investigated in the future, such as how the advantages in each visual field act in the IOR generation. To this purpose, and in accordance with the present results, the visual field effect should be taken into account in future designs.

\section{Acknowledgments}

This study was supported by grants from the Spanish MICINN (PSI2010-21427) and Xunta de Galicia (10PXIB211220PR). S.D. was supported by an Isidro Parga Pondal contract (Xunta de Galicia, Spain).

\section{References}

Amenedo, E., Pazo-Álvarez, P., Cadaveira, P., 2007. Vertical asymmetries in pre-attentive detection of changes in motion direction. Int. J. Psychophysiol. 64 (2), 184-189.

Andersen, S.K., Müller, M.M., Hillyard, S.A., 2009. Color-selective attention need not be mediated by spatial attention. J. Vis. 9 (6), 1-7.

Cameron, E.L., Tai, J.C., Carrasco, M., 2002. Covert attention affects the psychometric function of contrast sensitivity. Vis. Res. 42, 949-967.

\section{Post-print (final draft post-refereeing)}


Carrasco, M., Williams, P.E., Yeshurun, Y., 2002. Covert attention increases spatial resolution with or without masks: support for signal enhancement. J. Vis. 2, 467-479.

Castel, A.D., Chasteen, A.L., Scialfa, C.T., Pratt, J., 2003. Adult age differences in the time course of inhibition of return. J. Gerontol. Psychol. Sci. 58B, 256-259.

Chen, Q., Fuentes, L.J., Zhou, X., 2010. Biasing the organism for novelty: a pervasive property of the attention system. Hum. Brain Mapp. 31 (8), 1146-1156.

Corbetta, M., Shulman, G.L., 2002. Control of goal-directed and stimulus-driven attention in the brain. Nat. Rev. Neurosci. 3, 201-215.

Czigler, I., Balazs, L., Pato, L.G., 2004. Visual change detection: event-related potentials are dependent on stimulus location in humans. Neurosci. Lett. 364, 149-153.

Di Russo, F., Martínez, A., Sereno, M.I., Pitzalis, S., Hillyard, S.A., 2001. Cortical sources of the early components of the visual evoked potential. Hum. Brain Mapp. 15, 95-111.

Doallo, S., Lorenzo-López, L., Vizoso, C., Rodriguez Holguín, S., Amenedo, E., Bará, S., Cadaveira, F., 2004. The time course of the effects of central and peripheral cues on visual processing: an eventrelated potentials study. Clin. Neurophysiol. 115, 199-210.

Du, Y., Zhang, J.X., Xiao, Z., Wu, R., 2007. Neural systems and time course of proactive interference in working memory. Proceedings of the 29th Annual International Conference of the IEEE EMBS, pp. 1136-1139.

Eimer, M., 1994. An ERP study on visual spatial priming with peripheral onsets. Psychophysiology 31, 154-163.

Fioretto, M., Gandolfo, E., Orione, C., Fatone, M., Rela, S., Sannita, W.G., 1995. Automatic perimetry and visual P300: differences between upper and lower visual fields stimulation in healthy subjects. J. Med. Eng. Technol. 19, 80-83.

Fuchs, I., Ansorge, U., 2012. Inhibition of return is no hallmark of exogenous capture by unconscious cues. Front. Hum. Neurosci. 6, 1-8.

Fuentes, L.J., Vivas, A.B., Humphreys, G.W., 1999. Inhibitory tagging of stimulus properties in inhibition of return: effects on semantic priming and flanker interference. Q. J. Exp. Psychol. 52A (1), 149164.

Fuller, S., Rodríguez, R.Z., Carrasco, M., 2008. Apparent contrast differs across the vertical meridian: visual and attentional factors. J. Vis. 8 ((1):16), 1-16.

Gajewski, P.D., Stoerig, P., Falkenstein, M., 2008. ERP- correlates of response selection in a response conflict paradigm. Brain Res. 1189, 127-134.

Gratton, G., Coles, M.G.H., Donchin, E., 1983. A new method for off-line removal of ocular artifact. Electroencephalogr. Clin. Neurophysiol. 55, 468-484.

Handy, T.C., Jha, A.P., Mangun, G.R., 1999. Promoting novelty in vision: inhibition of return modulates perceptual-level processing. Psychol. Sci. 10 (2), 157-161.

He, S., Cavanagh, P., Intriligator, J., 1996. Attentional resolution and the locus of visual awareness. Nature 383, 334-337.

\section{Post-print (final draft post-refereeing)}


Hilchey,M.D., Satel, J., Ivanoff, J., Klein, R.M., 2013. On the nature of the delayed inhibitory cueing effects generated by uninformative arrows at fixation. Psychon. Bull. Rev. 20, 593-600.

Hopf, J.-M., Luck, S.J., Girelli, M., Hagner, T., Mangun, G.R., Scheich, H., Heinze, H.-J., 2000. Neural sources of focused attention in visual search. Cereb. Cortex 10, 1233-1241.

Hopf, J.-M., Boelmans, K., Schoenfeld, M.A., Luck, S.J., Heinze, H.-J., 2004. Attention to features precedes attention to locations in visual search: evidence from electromagnetic brain responses in humans. J. Neurosci. 24 (8), 1822-1832.

Hopfinger, J.B., Mangun, G.R., 1998. Reflexive attention modulates processing of visual stimuli in human extrastriate cortex. Psychol. Sci. 9 (6), 441-447.

Hopfinger, J.B., Mangun, G.R., 2001. Tracking the influence of reflexive attention on sensory and cognitive processing. Cogn. Affect. Behav. Neurosci. 1 (1), 56-65.

Hu, F.K., Samuel, A.G., 2011. Facilitation versus inhibition in non-spatial attribute discrimination tasks. Atten. Percept. Psychophys. 73, 784-796.

Hu, F.K., Samuel, A.G., Chan, A.S., 2011. Escape frominhibition of return by changing a salient, nonspatial attribute in a complex environment. J. Exp. Psychol. Gen. 140 (1), 35-50.

Ivanoff, J., Klein, R.M., 2001. The presence of a nonresponding effector increases inhibition of return. Psychon. Bull. Rev. 2, 307-314.

Ivanoff, J., Klein, R.M., 2006. Inhibition of return: sensitivity and criterion as a function of response time. J. Exp. Psychol. Hum. Percept. Perform. 32 (4), 908-919.

Ivanoff, J., Klein, R.M., Lupiañez, J., 2002. Inhibition of return interactswith the Simon effect: an omnibus analysis and its implications. Atten. Percept. Psychophys. 64 (2), 318-327.

Karim, A.K., Kojima, H., 2010. The what and why of perceptual asymmetries in the visual domain. Adv. Cogn. Psychol. 15 (6), 103-115.

Kingstone, A., Pratt, J., 1999. Inhibition of return is composed of attentional and oculomotor processes. Percept. Psychophys. 61 (6), 1046-1054.

Klein, R.M., 2000. Inhibition of return. Trends Cogn. Sci. 4 (4), 138-147.

Klein, R.M.,MacInnes, J., 1999. Inhibition of return is a foraging facilitator in visual search. Psychol. Sci. 10 (4), 346-352.

Klein, R.M., Shore, D.I., 2000. Relations among modes of visual orienting. In: Monsell, S.,Driver, J. (Eds.), Attention \& Performance XVIII: Control of Cognitive Processes. MIT Press, Cambridge, MA, pp. 195-208.

Klimesch,W., 2011. Evoked alpha and early access to the knowledge system: the P1 inhibition timing hypothesis. Brain Res. 1408, 52-71.

Kwak, H.-W., Egeth, H., 1992. Consequences of allocating attention to location and to other attributes. Percept. Psychophys. 51 (5), 455-464.

\section{Post-print (final draft post-refereeing)}


Langley, L.K., Fuentes, L.J., Hochhalter, A.K., Brandt, J., Overmier, J.B., 2001. Inhibition of return in aging and Alzheimer's disease: performance as a function of task demands and stimulus timing. J. Clin. Exp. Neuropsychol. 23 (4), 431-446.

Langley, L.K., Vivas, A.B., Fuentes, L.J., Bagne, A.G., 2005. Differential age effects on attention-based inhibition: inhibitory tagging and inhibition of return. Psychol. Aging 20 (2), 356-360.

Langley, L.K., Fuentes, L.J., Vivas, A.B., Saville, A.L., 2007. Aging and temporal patterns of inhibition of return. J. Gerontol. 2, 71-77.

Levine, M.W., McAnany, J.J., 2005. The relative capabilities of the upper and lower visual hemifields. Vis. Res. 45, 2820-2830.

Luck, S.J., Woodman, G.E., Vogel, E.K., 2000. Event-related potential studies of attention. Trends Cogn. Sci. 4, 432-440.

Lupiañez, J., Decaix, C., Siéroff, E., Chokron, S., Milliken, B., Bartolomeo, P., 2004. Independent effects of endogenous and exogenous spatial cueing: inhibition of return at endogenously attended target locations. Exp. Brain Res. 159 (4), 447-457.

McDonald, J.J., Ward, L.M., Kiehl, K.A., 1999. An event-related brain potential study of inhibition of return. Percept. Psychophys. 61 (7), 1411-1423.

McDonald, J.J., Hickey, C., Green, J.J.,Whitman, J.C., 2009. Inhibition of return in the covert deployment of attention: evidence from human electrophysiology. J. Cogn. Neurosci. 21 (4), 725-733.

Pastötter, B., Hanslmayr, S., Bäuml, K.H., 2008. Inhibition of return arises from inhibitionof response processes: an analysis of oscillatory beta activity. J. Cogn. Neurosci. 20 (1), 65-75.

Portin, K., Vanni, S., Virsu, V., Hari, R., 1999. Stronger occipital cortical activation to lower than upper visual field stimuli. Neuromagnetic recordings. Exp. Brain Res. 124, 287-294.

Posner, M.I., Cohen, Y., 1984. Components of Visual Orienting. Attention and Performance X: Control of Language Processes. In: Bouma, H., Bonwhuis, D. (Eds.), Erlbaum, Hillsdale, N. J, pp. 551556.

Posner, M.I., Petersen, S.E., 1990. The attention system of the human brain. Annu. Rev. Neurosci. 13, $25-42$.

Posner, M.I., Rafal, R.D., Choate, L.S., Vaughan, J., 1985. Inhibition of return: neural basis and function. Cogn. Neuropsychol. 2, 211-228.

Potts, G.F., 2004. An ERP index of task relevance evaluation of visual stimuli. Brain Cogn. 56, 5-13.

Prime, D.J., Jolicoeur, P., 2009. Response-selection conflict contributes to inhibition of return. J. Cogn. Neurosci. 21 (5), 991-999.

Prime, D.J., Ward, L.M., 2004. Inhibition of return from stimulus to response. Psychol. Sci. 15 (4), 272276.

Prime, D.J., Ward, L.M., 2006. Cortical expressions of inhibition of return. Brain Res. 1072 (1), 161-174.

Prime, D.J., Visser, T.A.W.,Ward, L.M., 2006. Reorienting attention and inhibition of return. Percept. Psychophys. 68 (8), 1310-1323.

\section{Post-print (final draft post-refereeing)}


Raymond, J.E., 1994. Directional anisotropy of motion sensitivity across the visual field. Vis. Res. 34, $1029-1037$.

Rezec, A.A., Dobkins, K.R., 2004. Attentional weighting: a possible account of visual field asymmetries in visual search? Spat. Vis. 17, 269-293.

Riggio, L.,Patteri, I., Umiltà,C., 2004. Location and shape in inhibition of return. Psychological Research $68,41-54$.

Ro, T., Pratt, J., Rafal, R.D., 2000. Inhibition of return in saccadic eyemovements. Exp. Brain Res. 130 (2), 264-268.

Satel, J., Wang, Z., Hilchey, M.D., Klein, R.M., 2012. Examining the dissociation of retinotopic and spatiotopic inhibition of return with event-related potentials. Neurosci. Lett. 524, 40-44.

Satel, J., Hilchey, M.D., Wang, Z., Story, R., Klein, R.M., 2013. The effects of ignored versus foveated cues upon inhibition of return: an event-related potential study. Atten. Percept. Psychophys. 75 (1), 29-40.

Spence, C., Lloyd, D., McGlone, F., Nichols, M.E.R., Driver, J., 2000. Inhibition of return is supramodal: a demonstration between all possible pairings of vision, touch and audition. Exp. Brain Res. 134, $42-48$.

Taylor, T.L., Klein, R.M., 1998a. On the causes and effects of inhibition of return. Psychon. Bull. Rev. 5 (4), 625-643.

Taylor, T.L., Klein, R.M., 1998b. Inhibition of return to color: a replication and nonextension of Law, Pratt, and Abrams (1995). Percept. Psychophys. 60 (8), 1452-1456.

Taylor, T.L., Klein, R.M., 2000. Visual and motor effects in inhibition of return. J. Exp. Psychol. Hum. Percept. Perform. 26 (5), 1639-1656.

Thomas, N.A., Elias, L.J., 2011. Upper and lower visual field differences in perceptual asymmetries. Brain Res. 1387, 108-115.

Tian, Y., Yao, 2008. A study on the neuralmechanism of inhibition of return by the eventrelated potential in the Go/Nogo task. Biol. Psychol. 79, 171-178.

Tian, Y., Chica, A.B., Xu, P., Yao, D., 2011a. Differential consequences of orienting attention in parallel and serial search: an ERP study. Brain Res. 1391, 81-92.

Tian, Y., Klein, R.M., Satel, J., Xu, P., Yao, 2011b. Electrophysiological explorations of the cause and effect on inhibition of return in a cue-target paradigm. Brain Topogr. 24, 164-182.

Van der Lubbe, R.H.J., Vogel, R.O., Postma, A., 2005. Different effects of exogenous cues in a visual detection and discrimination task: delayed attention withdrawal and/or speeded motor inhibition? J. Cogn. Neurosci. 17 (12), 1829-1840.

Vogel, E.K., Luck, S.J., 2000. The visual N1 component as an index of a discrimination process. Psychophysiology 37, 190-203.

Wang, P., Fuentes, L.J., Vivas, A.B., Chen, Q., 2013. Behavioural and neural interaction between spatial inhibition of return and the Simon effect. Front. Hum. Neurosci. 7, 572.

\section{Post-print (final draft post-refereeing)}


Wascher, E., Tipper, S.P., 2004. Revealing effects of noninformative spatial cues: an EEG study of inhibition of return. Psychophysiology 41, 716-728.

Zhang, Y., Zhou, X., Zhang, M., 2012. Temporary inhibitory tagging at previously attended locations: evidence from event-related potentials. Psychophysiology 49 (9), 1191-1199.

Chica, A.B., Lupiáñez, J., 2009. Effects of endogenous and exogenous attention on visual processing: an inhibition of return study. Brain Res. 1278, 75-85.

Chica, A.B., Lupiáñez, J., Bartolomeo, P., 2006. Dissociating inhibition of return from endogenous orienting of spatial attention: evidence from detection and discrimination tasks. Cogn. Neuropsychol. 23 (7), 1015-1034.

Chica, A.B., Lasaporana, S., Lupiáñez, J., Doricchi, F., Bartolomeo, P., 2010. Exogenous attention can capture perceptual consciousness: ERP and behavioural evidence. Neuroimage 51, 1205-1212.

Chica, A.B., Bartolomeo, P., Lupiáñez, J., 2013. Two cognitive and neural systems for endogenous and exogenous spatial attention. Behav. Brain Res. 237, 107-123

\section{Post-print (final draft post-refereeing)}



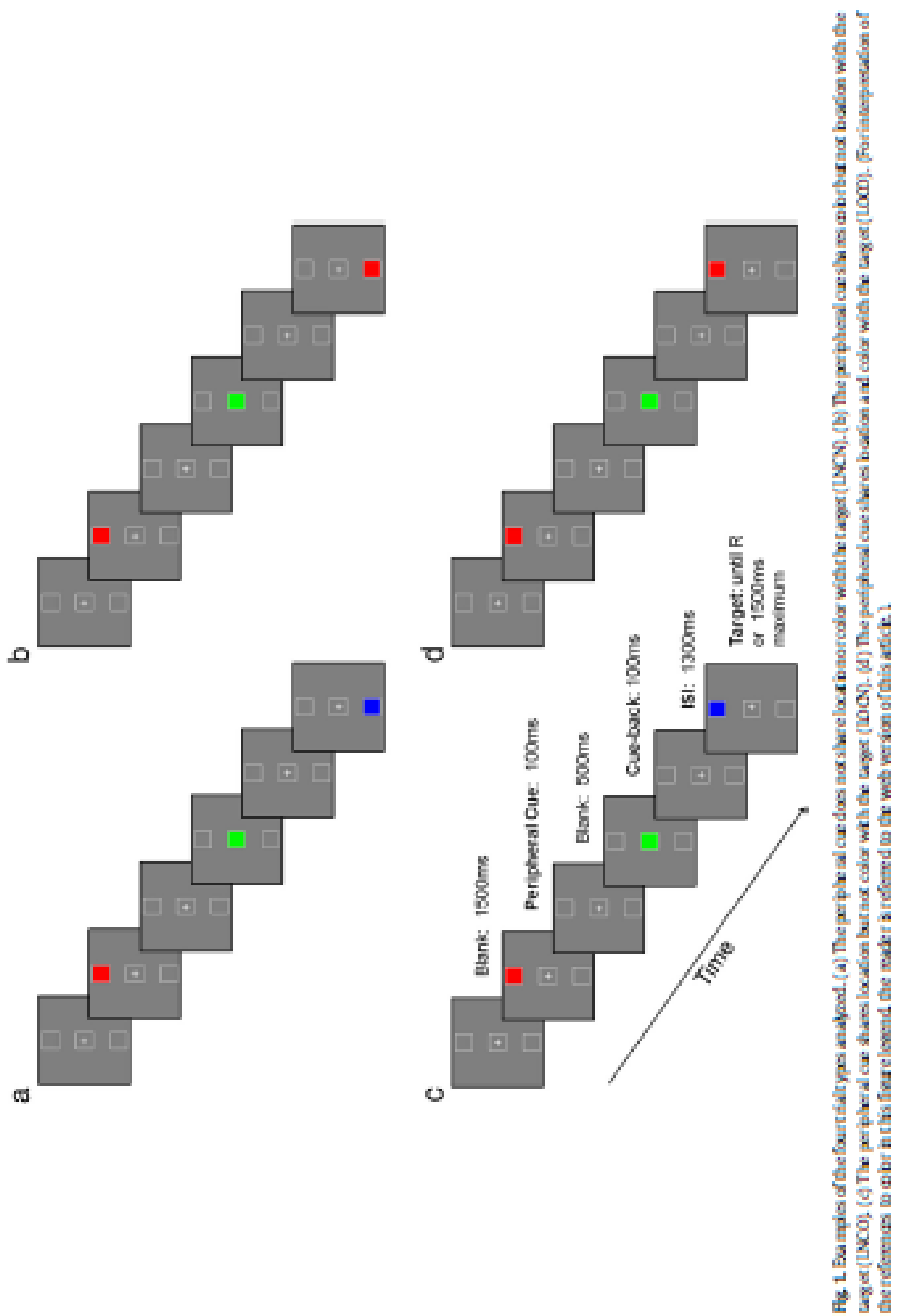

Post-print (final draft post-refereeing) 


\section{Titt 1}

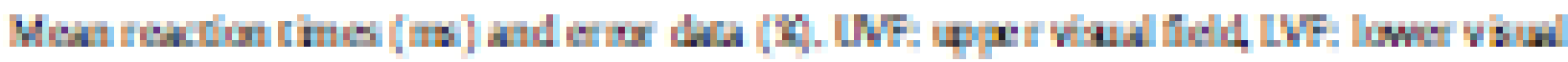

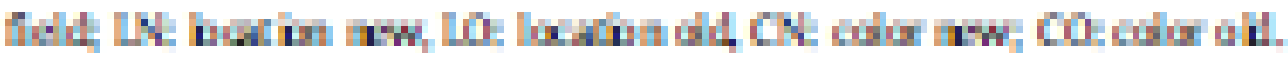

\begin{tabular}{|c|c|c|c|c|}
\hline $\begin{array}{l}\text { Full } \\
\text { Full }\end{array}$ & $\begin{array}{l}\text { Cu: } \\
\text { condition }\end{array}$ & $\begin{array}{l}\text { Mut ITT } \\
\text { buldww! }\end{array}$ & 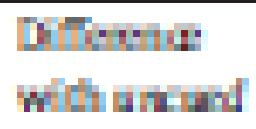 & 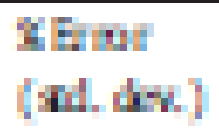 \\
\hline \multirow[t]{4}{*}{ WF } & LAS & $94.217(14.4)$ & & 174 (1.A6) \\
\hline & $\mathrm{m} N$ & $5 x .72(14.14)$ & 12504 & 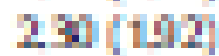 \\
\hline & Hä & 펫11 (4⿴囗十) & 444 & 14,242 \\
\hline & war & s.t. (14k) & $1+42$ & 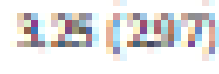 \\
\hline \multirow[t]{4}{*}{ MF } & LNA & 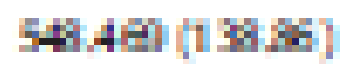 & & 246 (201] \\
\hline & $\cos$ & 페.54 [4 & 1107 & 25127 \\
\hline & WNA & 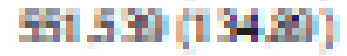 & 9070 & 19 (170) \\
\hline & $\operatorname{mos}$ & $54.74(1+111)$ & $\tan n$ & $270(215)$ \\
\hline
\end{tabular}

Post-print (final draft post-refereeing) 
FC1
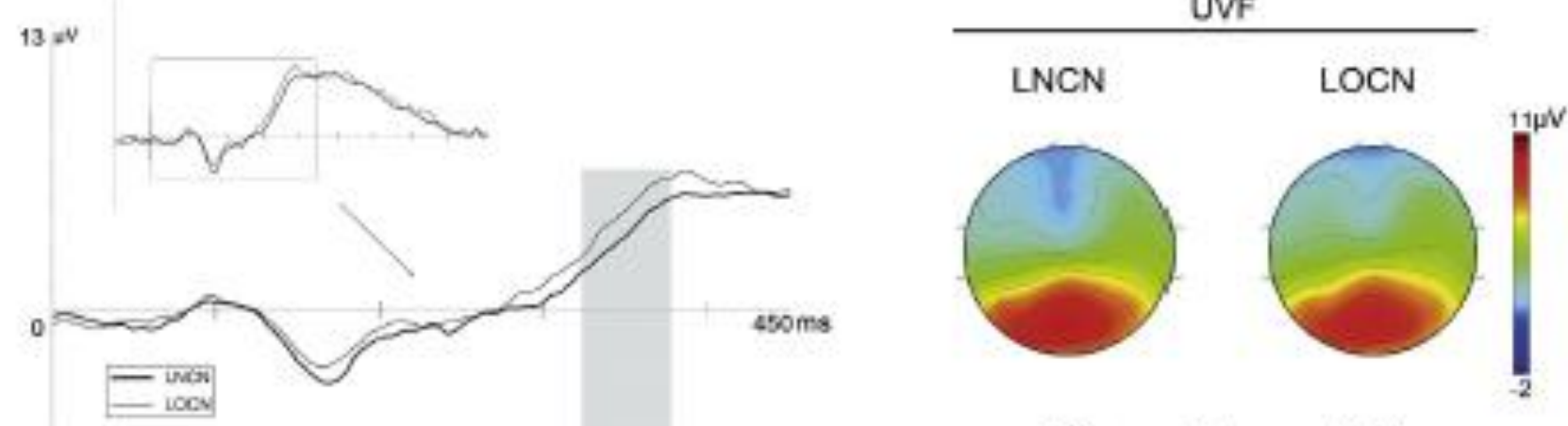

$-7$
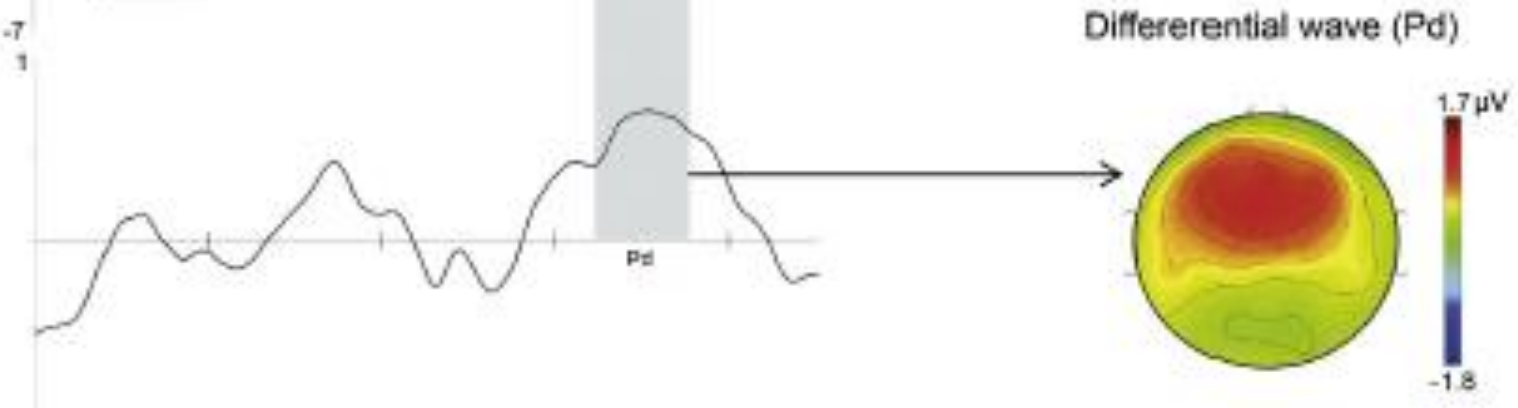

$-15$

POT

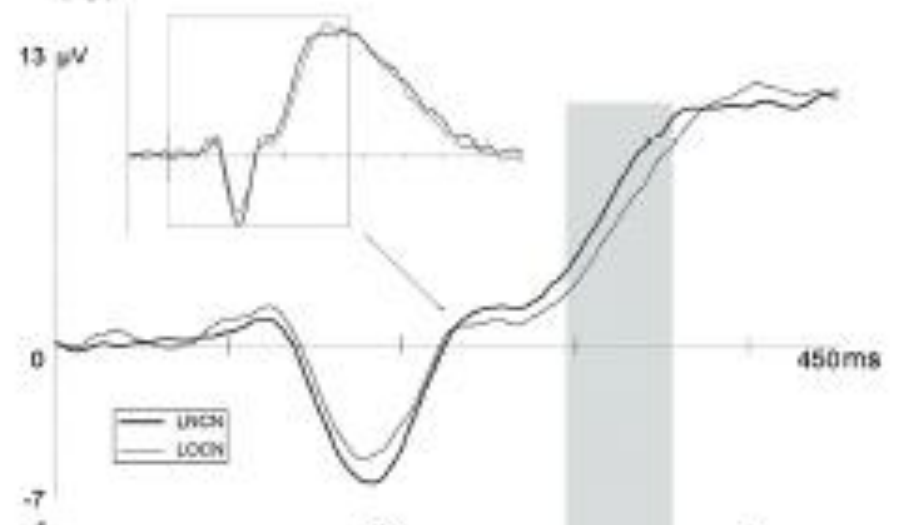

-7
1

4.5

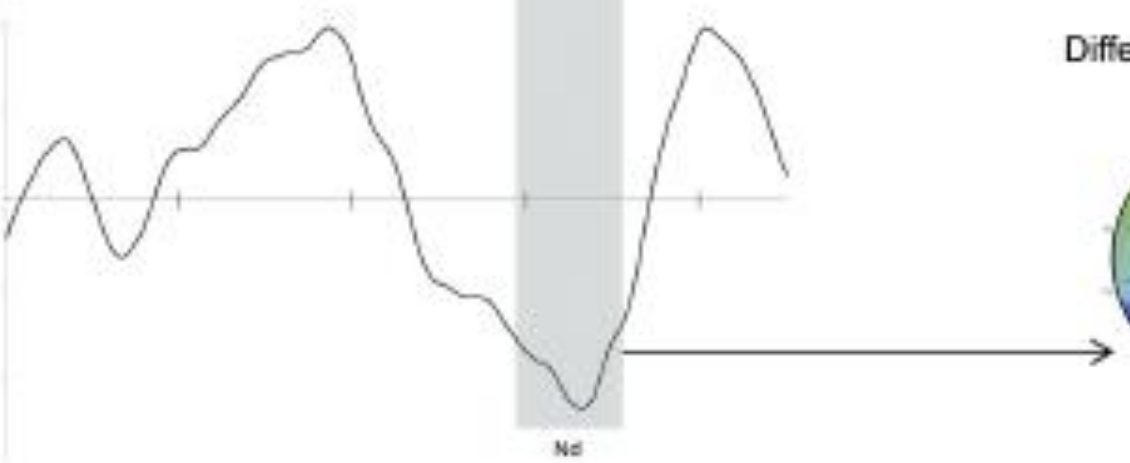

Differenential wave (Nd)

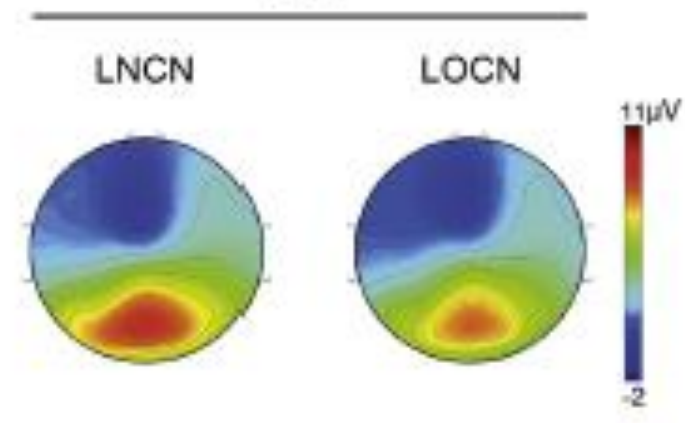

Ciferential wave (Nd)

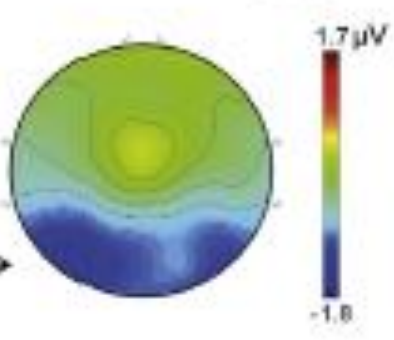

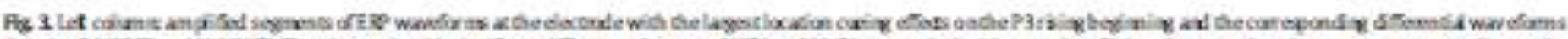

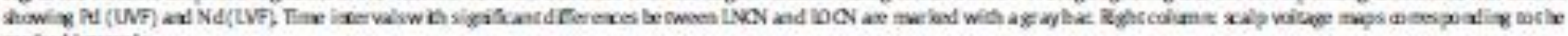
moked inervals 


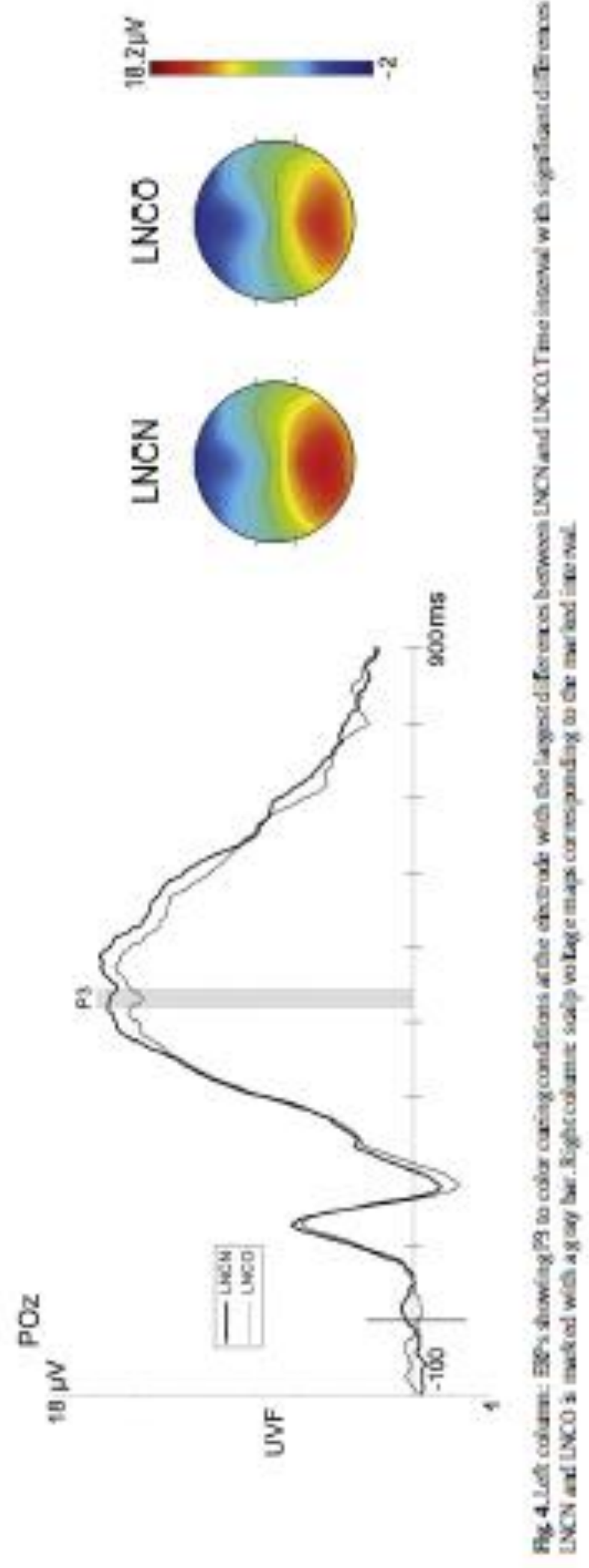

Post-print (final draft post-refereeing) 

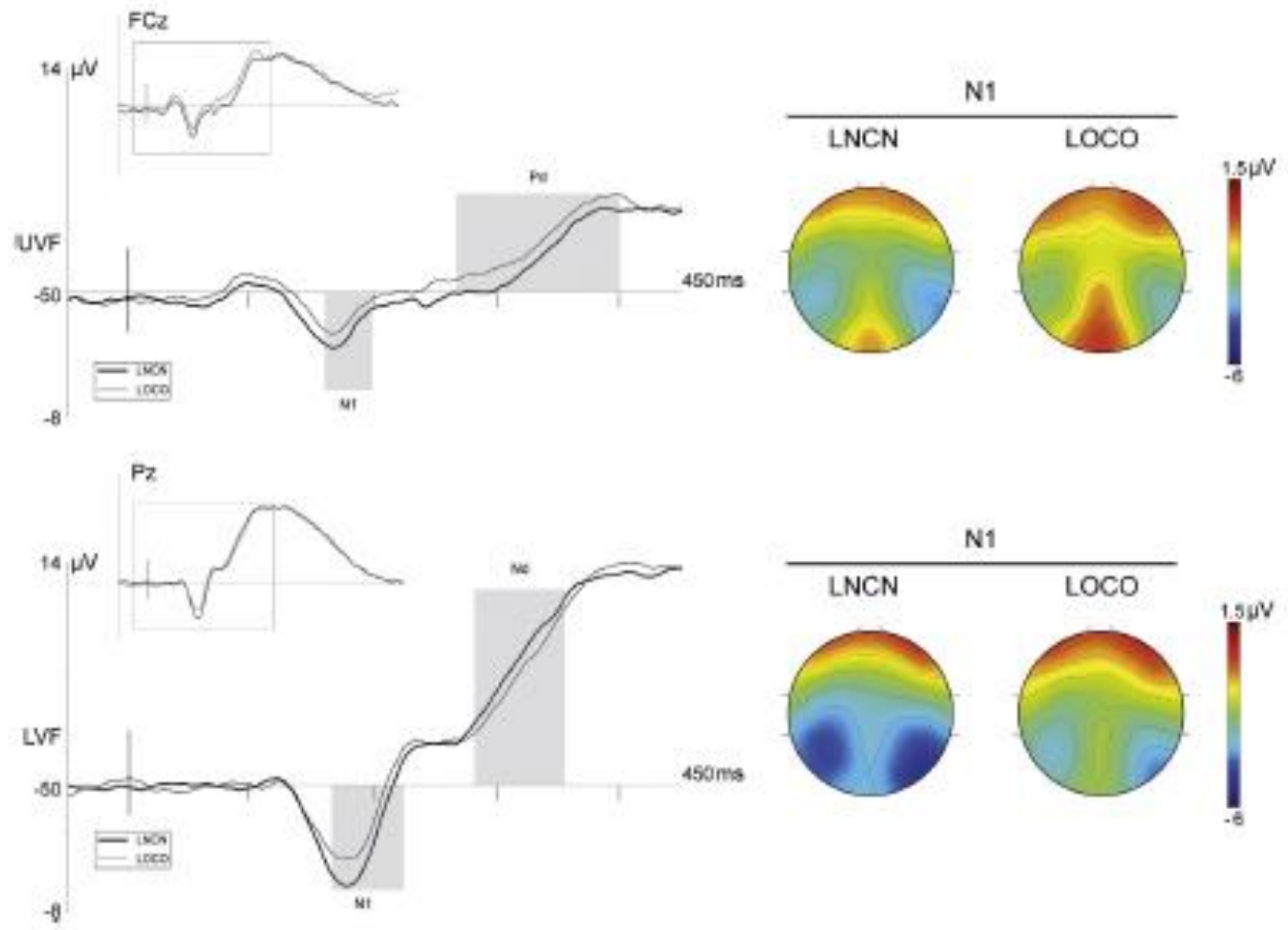

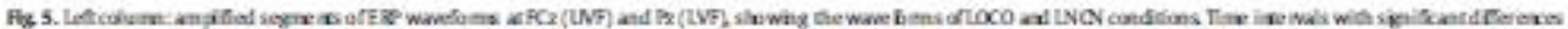

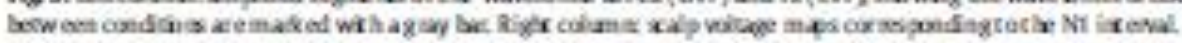

Post-print (final draft post-refereeing) 